\title{
Factors influencing subject selection in upper secondary education (Key Stage 4) for males and females in England
}

\author{
Joanne Vaughan ${ }^{A, B, D, E, F}$, Daniel Boduszek ${ }^{C, D, E}$, Alison Rodriguez ${ }^{A, E, F}$ \\ Department of Behavioural and Social Sciences, University of Huddersfield, Huddersfield, West Yorkshire, UK
}

\section{BACKGROUND}

Research to date has investigated the potential factors that influence students' decisions in opting to study certain subjects during their upper secondary education. Trends in subject selection at this level (Key Stage 4) have been maintained over time and have consistently displayed comparable differences for males and females. It is recognised that males typically opt for subjects such as physical education and science, while females are traditionally noted as favouring the arts and humanities. These educational decisions may impact on future occupational directions. In light of recent initiatives, such as the English Baccalaureate, it is of interest to explore whether such measures have had an influence on this noted gender gap.

\section{PARTICIPANTS AND PROCEDURE}

The present study investigates the potential predictors of subject selection, while controlling for gender, offering a specific focus on the education system in England. Attention is given to students' perceived academic ability and attitude toward school, and how such factors may guide subject choice. Participants $(N=276)$ were students currently in the process of selecting optional modules for Key Stage 4 study.

\section{RESULTS}

The findings demonstrate that female students are less likely than their male counterparts to opt for physical education (PE) and business studies/information and communication technology (ICT) as preferred modules, in comparison to 'creative and performance' subjects (reference category). Higher levels of reported masculinity were also shown to relate to the up-take of PE at Key Stage 4.

\section{CONCLUSIONS}

The implications of these findings are discussed in relation to existing research and practical contributions to the educational arena.

\section{KEY WORDS}

school subject selection; upper secondary education; Key Stage 4; gender

CORRESPONDING AUthor - Daniel Boduszek, Ph.D., Department of Behavioural and Social Sciences, University of Huddersfield, Queensgate, Huddersfield, HD1 3DH, West Yorkshire, UK, e-mail: d.boduszek@hud.ac.uk AUthors' CONTRIBUtion - A: Study design - B: Data collection - C: Statistical analysis - D: Data interpretation .

E: Manuscript preparation - F: Literature search · G: Funds collection

TO CITE THIS ARTICLE - Vaughan, J., Boduszek, D., \& Rodriguez, A. (2015). Factors influencing subject selection in upper secondary education (Key Stage 4) for males and females in England. Current Issues in Personality Psychology, 3(3), 166-174.

RECEIVED 14.07.2015 · REVIEWED 28.07.2015 · ACCEPTED 05.08.2015 · PUBLISHED 17.08.2015 


\section{BACKGROUND}

The introduction of the National Curriculum by the Education Act 1988 made it compulsory for males and females to study the same curriculum. It was expected that this initiative would potentially limit the gender diversity in school subjects studied that had been previously documented (Francis, 2000). Despite this opportunity for gender equality within schools (DfE, 2013), the educational arena remains dominated by traditional gender trends for subject preference and selection at upper secondary level education (Colley \& Comber, 2003). Related studies concur, supporting the existence of subject gender bias regardless of policies aiming to reduce/remove it (Moon, Lilley, Morgan, Gray, \& Krechowiecka, 2004). Male dominance is discussed in research looking at students choosing science, technology, engineering and mathematics (STEM) subjects in England (Francis, 2000), the Netherlands and the US. A gender difference has also been noted, with girls perceiving STEM subjects to be more difficult in Italy (Muzzatti \& Agnoli, 2007), and Canada (Crombie et al., 2005), suggesting that subject gender bias is not restricted to the education system in England.

Drawing on behavioural principles, it could be suggested that gender bias is maintained through interactions within the environment (Skinner, 1974). In line with social learning theory (Bandura, 1977) and the notion of sex-role socialisation, it may be that extrinsic influences operating at different levels within the social world may directly and indirectly impact upon a student's choice of subject selection. Davies, Telhaj, Hutton, Adnett and Coe (2008) acknowledged a potential parental influence and noted that the socio-economic background of parents played a part in students' educational direction, possibly via modelling. Females and students from less privileged socio-economic backgrounds are generally less likely to pursue STEM subjects than their male or more privileged peers. Thomas and Webber (2009) further support the notion of both parents and peers as having an influential role on the decisions made about, and attitudes towards, school. Additional research has suggested that students with greater perceived support from parents, teaching staff and peers had a more positive attitude towards such subjects and a higher sense of self-competence (Rice, Barth, Guadagno, Smith, \& McCallum, 2013).

An alternative perspective based on a review of educational experience indicated that gender differences in education may, in part, relate to a preference of assessment styles (Lord \& Harland, 2000). Females were reported to prefer course work style assessment as a measure of achievement, while males generally displayed a more favourable attitude towards examinations and assessments of this type. This would comply with the documented trends for males and females and their chosen optional subjects at upper secondary level education (Francis, 2000). STEM subjects are typically more exam-based, while subjects within the humanities may be more coursework/ portfolio styled.

In further reference to assessment styles, Adey and Biddulph (2001) suggested that the anticipation of a heavy written workload may have a deterrent effect on the number of students wishing to study subjects such as history, as they expect that they will not enjoy it. It was noted in this survey that subject enjoyment was influenced by the methods of teaching employed and that such acknowledged enjoyment increased the positive attitude towards education. However, there was a large discrepancy between reported enjoyment in history and/or geography and opting to study such subjects at Key Stage 4. This demonstrated that enjoyment alone is not a strong predictor of the up-take of an optional school subject. The pertinent literature on the impact of enjoyment is also not clear on the strength of factors which discourage or encourage the perception of enjoyment and how this may relate to attitudes, academic self-perceptions and subject selection.

A wealth of research has indicated that a student's self-perception of academic ability has a direct impact on subject selection, with the individual being more inclined to opt for subjects in which they believe they will be most academically successful (Reiss, 2001). Ashworth and Evans (2001) suggest that a positive school self-concept and belief in personal ability to attain a good grade may also promote subject enjoyment and impact upon subject selection. Linnenbrink and Pintrich (2003) propose an intrinsic motivation for learning and engagement in education as highly influenced by perceived self-efficacy. Conflicting findings have been documented for students' self-assessed abilities in relation to gender and are worthy of further consideration.

McCrone, Morris, and Walker (2005) suggest that males often display a higher academic self-perception than females, although Francis (2000) reported that students supported gender equality in terms of overall academic capabilities. However, the latter study employed direct interviews with a female researcher, which may have impacted students' response as participants may have been more likely to verbalise a gender-neutral response; while equal gender ability was noted, the study did highlight gender diversity for different subjects, which supported previously reported male/female trends. Most related research has employed the survey method to promote anonymous responses, which may yield more accurate data by providing discretion. The general trend obtained via this approach supports male dominance of self-assessed academic ability. Interestingly, these findings are in contrast to performance statistics, as females 
tend to outperform males at Key Stage 4 (Brown, 2010).

The development of the said academic self-perception may be related to social comparison theory (Festinger, 1954) as students compare their abilities to those around them as a means of self-evaluation. Research by Ryan (2001) illustrated that for low academic achievers there is a noted decline in motivation throughout the course of school. It was further proposed that students are more inclined to identify with other students who share similar academic characteristics. Thus, academic ability, or perceived ability, can render certain students vulnerable to a negative attitude toward school, a disinterest with education generally and certain subjects specifically. Ireson, Hallam, and Hurley (2001) suggested that students had an overall negative attitude towards school and education when categorised on the basis of demonstrated academic ability. The study highlighted that students in the lower academic bands were made to feel inadequate, affecting their attitude toward school and feelings of self-worth. Students from the higher bands also acknowledged an influence due to labelling; being perceived as more academically able made students feel under greater pressure to perform well, impacting on their attitude toward school in general. Colley and Comber (2003) propose that students generally display a preference for either academic or vocational pathways, which may be a demonstrative consequence of ability.

Rice et al. (2013) considered perceived abilities and attitudes towards maths and science, with these findings indicating a positive effect. It was shown that students with greater support from parents, staff and peers had a more positive attitude to these subjects and a higher sense of self-competence. Ashworth and Evans (2001) also suggest a multitude of influences on the development of an academic self-concept in young people, suggesting that external and internal aspects of education are not isolated but may operate together to influence choice. Staff preference and pedagogy (Francis, 2000) have also been shown to relate to subject selection. Ashworth and Evans (2001) note that teaching professionals may unintentionally influence educational decisions, both directly and indirectly based on gender.

It is arguably difficult to change and challenge educational assumptions, whether these are related to social structures or attitude towards an academic subject (McCrone et al., 2005). If one considers post-structuralist theory, which posits gender as a performance and moves the understanding of gender away from the binary understanding of sex attached to gender, then it is possible to promote a gender-sensitive pedagogy (Sinnes, 2006). If teaching is structured around individual experiences and interests and teachers accept that there might be differences in perceptions of subject areas as influenced by gender attributes (Colley \& Comber, 2003), there is an opportunity to encourage interest in subject areas for all students (Sinnes, 2006).

Literature pertaining to students' choices of subjects selected for study at Key Stage 4 has recognised a multitude of factors that impact upon this decision; these factors, both extrinsic and intrinsic, are often acknowledged as co-existing, highlighting an inter-relatedness of potential influences which can facilitate the prediction of specific subject up-take in male and female students. Brown (2010) suggests that school subjects selected for study and occupational choices may be mutually reinforcing, and it is justified to posit that subjects chosen for optional study may limit or promote potential future directions. Francis Khurana, and Pereira (2003) note that female occupational aspirations have diversified over recent years and are less gender-stereotypical than has been previously documented. While the number of women entering professional occupations has risen, there still remains a clear gender divide for certain career routes such as science (Blickenstaff, 2005).

In acknowledging the mutual reinforcement of school subject selection and future career pathways (Francis, 2002), extended exploration into the trends of subject up-take for males and females is required. Of paramount importance throughout this field of study is the influence of gender. Furthermore, in light of recent initiatives such as the English Baccalaureate in 2010, it is of interest to explore whether such measures have had an effect on teaching and the 'gender gap' (the English Baccalaureate is a performance measure which recognises students who have achieved a grade $\mathrm{C}$ or above in a diverse range of core subjects: English, mathematics, history or geography, science and a modern foreign language) (DfE, 2013). Further research refined to permit a greater focus on potential predictors such as perceived ability and attitudes to education is necessary to enhance knowledge. This may be beneficial to informing future initiatives to promote and maintain gender equality within the educational arena. More specifically, it is appropriate to investigate the up-take of school subjects selected for study at Key Stage 4 while controlling for gender; this is because such choices influence subject choices that students are able to pursue following their compulsory education.

\section{AIMS OF THE STUDY}

The current study aimed to:

1. Investigate which school subjects students opt to study at upper secondary level in England.

2. Explore which predictors are the most relevant to influencing subject selection.

3. Investigate the said predictors while controlling for gender. 


\section{PARTICIPANTS AND PROCEDURE}

\section{SAMPLE}

The participants $(N=276)$ were 149 male and $127 \mathrm{fe}$ male students aged $12-15$ years $(M=13.57, S D=0.70)$. Participants were from three mixed secondary schools in Yorkshire $(n=80, n=86$ and $n=110)$. Participants ranged from year 8 to year 9 depending on the year in which their attended school offered subject selection opportunities. The inclusion criterion for participation was having made subject selections for study at Key Stage 4 within the last year or being in the process of doing so within the current academic year.

\section{MEASURES}

A questionnaire incorporating quantified responses and rating scales was designed and utilised for the current study; this provided a systematic way of enabling students to volunteer information about their attitudes, beliefs and behaviours.

Demographics: Demographic information (sex and age) was obtained and the subjects selected for study during Key Stage 4 were recorded within the questionnaire. School subjects were categorised into five groups: physical education/sport, creative and performance (art, design, drama, performing arts, health and beauty), business/ICT, humanities (history, geography, media, psychology, sociology) and Science (all natural sciences, technology and electronics). Mathematics and English were not included in the study as they are compulsory subjects which must be studied at Key Stage 4 by all students. The focus of the study is on subject choice and consequently only optional subjects were investigated and analysed. Science has been retained as an option within this study; this relates only to additional science modules which are separate from the core science that is studied by all students as part of the National Curriculum.

Attitude Toward School and Academic Self-Perception: The 'Attitudes Toward School (ATS)' and 'Academic Self-Perception (ASP)' scales derived from the School Attitudes Assessment Survey (McCoach, 2002) were included in the questionnaire. Both scales have a high reliability score: ATS $\alpha$ score $=.89$, ASP $\alpha$ score $=.88$ (Cronbach, 1951) . Both scales provide statements which are rated on a 7-point Likert scale format ranging from 1 = strongly disagree to $7=$ strongly agree. A higher total score indicates a more positive attitude toward school (ATS sub-scale; scale range 0-42) and a more positive academic self-assessment (ASP sub-scale; scale range 0-35).

Children's Sex Role Inventory: In order to assess sex typing and androgyny, the Children's Sex Role Inventory (CSRI) (Boldizar, 1991) was included in the questionnaire. This is a validated measure of masculinity (CSRI-M) and femininity (CSRI-F) and is recognised as the equivalent to Bem's Sex Role Inventory (SRI) (Bem, 1974). The short form of this scale containing 30 items was used in the questionnaire. The items on the scale were self-statements and participants rated themselves on a 4-point scale from $1=$ not true of me at all to $4=$ very true of me. A high total score on the masculine sub-scale (CSRI-M) indicated that the student was more masculine, and a high total score on the feminine sub-scale (CSRI-F) indicated that the student was more feminine.

\section{PROCEDURE}

Contact details for secondary schools were obtained online from local Council websites, leading to three secondary schools being invited to participate in the study. Consent of schools to partake was granted by the deputy head teachers and Key Stage 4 managers at each school. Under the supervision of teaching staff, the questionnaires were completed within the classroom environment to encourage a higher response rate. In order to control for differences in academic/vocational abilities, respondents were from all ability classes (exam boards generally offer a higher level and a foundation level paper for each subject, and schools often group classes accordingly - this ensures that the teaching offered within these specified classes is suitable for the level of exam that the student will undertake).

\section{RESULTS}

\section{DESCRIPTIVE STATISTICS}

Descriptive statistics and internal consistencies (Cronbach's $\alpha$ ) are presented in Table 1. Mean total scores for ATS and ASP are just above the mid-point on each scale, and total scores for masculinity and femininity on the CSRI are similar.

Frequency figures in Table 2 show that schools 'A' and 'B' had a similar number of participants and school ' $C$ ' had slightly more. The sample consisted of a comparable number of males and females. Humanities and creative/performance subjects were most commonly chosen for study at Key Stage 4; the remaining subjects were selected in similar frequencies.

\section{INDEPENDENT SAMPLES T-TEST}

Independent samples $t$-test was conducted to compare the ASP total scores of females $(n=149)$ with the ASP total scores for males $(n=127)$. There was a significant difference in total scores between the two 
Table 1

Mean scores and standard deviations of age, Attitude Toward School (ATS) scores, Academic Self-Perception (ASP) scores, and femininity (CSRI-F) and masculinity (CSRI-M) scores from the Children's Sex Role Inventory (CSRI)

\begin{tabular}{lccccc}
\hline Variable & $M$ & $S D$ & Min & Max & Cronbach's $\alpha$ \\
\hline Age & 13.57 & 0.70 & 12.00 & 15.00 & N/A \\
ATS & 24.12 & 8.05 & 6.00 & 42.00 & .89 \\
ASP & 25.00 & 6.14 & 5.00 & 35.00 & .91 \\
CSRI-F & 28.28 & 5.86 & 10.00 & 40.00 & .81 \\
CSRI-M & 25.84 & 5.84 & 10.00 & 38.00 & .80 \\
\hline
\end{tabular}

Table 2

Frequencies of participants from each school, gender and subjects selected for study at Key Stage 4

\begin{tabular}{lcc}
\hline Variable & Frequency & $\%$ \\
\hline School & & \\
A & 80 & 29.00 \\
B & 86 & 31.20 \\
C & 110 & 39.90 \\
Gender & & \\
male & 149 & 54.00 \\
female & 127 & 46.00 \\
Subject & & \\
creative/performance & 77 & 27.90 \\
physical education/sport & 35 & 12.70 \\
business/ICT & 32 & 11.60 \\
humanities & 96 & 34.80 \\
science & 36 & 13.00 \\
\hline
\end{tabular}

groups, $t(274)=-2.62, p=.001$, two-tailed, with males $(M=26.03, S D=5.53)$ scoring higher than females $(M=24.11, S D=6.50)$. The result suggests that males rate their academic self-perception more favourably than females. The magnitude of the difference in the means (mean difference $=-1.92,95 \% \mathrm{CI}:-3.36 /-0.47$ ) was small $(\eta$ squared $=.02)$.

In terms of the ATS, the data suggested no significant difference between the total scores for males and females, $t(188)=0.83, p=.407$, two-tailed.

\section{MULTINOMIAL LOGISTIC REGRESSION}

Multinomial logistic regression was used to analyse predictors for an unordered group classification, such as individuals who selected a particular subject $\left(\chi_{(20)}^{2}=55.92, p<.001\right)$ (see Table 3). The reference category for the outcome variable was 'creative and performance subjects'. Each of the other four categories of subjects (physical education/sport, business/ ICT, humanities and science) was compared to this reference group. The main interest of the analysis was focused on the relationship between students' attitudes toward school, their academic self-perception and their masculinity (CSRI-M) and femininity

Table 3

Multinomial logistic regression model of subject selection for study at Key Stage 4

\begin{tabular}{|c|c|c|c|c|c|c|c|c|}
\hline \multirow[t]{2}{*}{ Variable } & \multicolumn{2}{|c|}{$\begin{array}{c}\text { Physical education/ } \\
\text { sport }\end{array}$} & \multicolumn{2}{|c|}{ Business/ICT } & \multicolumn{2}{|c|}{ Humanities } & \multicolumn{2}{|l|}{ Science } \\
\hline & OR $(95 \% \mathrm{Cl})$ & SE & OR $(95 \% \mathrm{Cl})$ & SE & OR $(95 \% \mathrm{Cl})$ & SE & OR $(95 \% \mathrm{Cl})$ & SE \\
\hline \multicolumn{9}{|l|}{ Gender } \\
\hline female & $0.32(0.10 / 0.86)^{*}$ & .60 & $0.25(0.08 / 0.78)^{*}$ & .58 & $0.93(0.37 / 2.34)$ & .47 & $0.45(0.17 / 1.23)$ & .51 \\
\hline male & 1.00 & & 1.00 & & 1.00 & & 1.00 & \\
\hline ATS & $0.95(0.88 / 1.03)$ & .04 & $1.04(0.96 / 1.13)$ & .04 & $1.02(0.96 / 1.01)$ & .03 & $1.01(0.94 / 1.07)$ & .04 \\
\hline ASP & $0.99(0.89 / 1.11)$ & .06 & $0.99(0.89 / 1.11)$ & .06 & $1.08(0.98 / 1.18)$ & .05 & $1.05(0.95 / 1.16)$ & .05 \\
\hline CSRI-M & $1.13(1.01 / 1.27)^{*}$ & .06 & $0.92(0.83 / 1.02)$ & .05 & $0.93(0.86 / 1.01)$ & .04 & $1.01(0.92 / 1.11)$ & .05 \\
\hline CSRI-F & $0.91(0.82 / 1.01)$ & .05 & $0.93(0.84 / 1.04)$ & .06 & $1.01(0.92 / 1.11)$ & .05 & $0.95(0.86 / 1.05)$ & .05 \\
\hline
\end{tabular}

Note. Reference group: creative and performance; OR - odds ratio; SE - standard error; $95 \% \mathrm{Cl}-$ confidence interval; ${ }^{*} p<.05$, ${ }^{* *} p<.01,{ }^{* *} p<.001$ 
(CSRI-F) scores from the CSRI, while controlling for gender.

The first column in Table 3 shows the outcome of 'physical education/sport' compared to 'creative and performance subjects' (reference category). The results suggest that those students who score higher on the masculinity (CSRI-M) sub-scale of the CSRI are significantly more likely $(\mathrm{OR}=1.13)$ to select 'physical education/sport subjects' compared to 'creative and performance subjects'. In relation to gender, females (compared to males) were significantly less likely $(\mathrm{OR}=0.32)$ to select 'physical education/sport subjects' compared to 'creative and performance subjects'. The other predictors (Attitude Toward School, Academic Self-Perception and femininity scores) had no significant relevance for the selection of 'physical education/sport subjects' compared to 'creative and performance subjects' (reference category) for study at Key Stage 4 in this sample.

The second column in Table 3 has the outcome of 'business/ICT subjects' compared to 'creative and performance subjects' (reference category). The only significant predictor was gender. Females (compared to males) were significantly less likely $(\mathrm{OR}=0.25)$ to select 'business/ICT subjects' compared to 'creative and performance subjects'. No further significant results were found for predicting the selection of 'business/ICT subjects' for study at Key Stage 4 in this sample.

The results revealed no significant predictors when 'humanities' was compared to 'creative and performance subjects'. Also no significant results were obtained when 'science subjects' was compared to 'creative and performance subjects'.

\section{DISCUSSION}

Several key points have been identified in the current study with respect to optional subject choice at upper secondary level and gender. Higher levels of reported masculinity are shown to be associated with a preference for physical education/sports. In addition, females are significantly less likely than males to select physical education and business studies/ICT in comparison to 'creative and performance' modules. A gender difference in self-perceptions of ability was also noted, with males rating themselves more academically competent than females. However, the reported academic ability of students and the attitudes they hold towards school did not predict the up-take of any school subjects within this sample.

Physical education (PE) has been acknowledged in this study as stereotypically a masculine subject. Increased levels of recognised masculine traits have been shown in this research to predict the likelihood of subject up-take. The current findings further corroborate previous research indicating a relationship between masculinity and a preference for PE (Colley \& Comber, 2003; Colley, Comber, \& Hargreaves, 1994). In contrast to the research that demonstrates a strong preference of males towards science (Colley \& Comber, 2003), the results of the current study do not concur with this trend. As a whole, science was less frequently chosen for study at Key Stage 4 than $\mathrm{PE}$ and 'creative and performance' subjects in this sample. One potential explanation may be that science is a compulsory subject at Key Stage 4 and as such is studied by both males and females regardless of preference or expressed choice. 'Science' as a subject within the current study only relates to additional optional science modules (dual science) at upper secondary level. The level of science up-take in this work may be skewed by the compulsory element of science within the National Curriculum. As such, it may be that science is a preferred subject for males, but, because they are already studying this subject, they choose to divert their optional choice toward a different area. Further investigation would be beneficial in clarifying the present results which indicate a changing trend.

In addition to $\mathrm{PE}$, the current study outcomes demonstrate that females were significantly less likely than males to opt for business/ICT subjects at Key Stage 4. This is in keeping with the existing literature, which acknowledges that females rate such subjects unfavourably (Francis, 2000). Business/ICT was the least selected subject overall in the sample, with only 32 participants opting to study it. Thus, while there is a noted difference in gender up-take within the sample, it would seem that the subject is less appealing overall to students as an optional study choice at Key Stage 4. It is possible to further propose that traditional patriarchal stereotypes are involved in the gender divide relating to these subjects and that socialisation plays a role in maintaining such viewpoints (Bandura, 1977).

The findings of the current research can also be considered with reference to initiatives within the educational arena. Due to the introduction of the English Baccalaureate in 2010, it may be suggested that the apparent preference for the option of 'humanities' in this sample is a direct result of this performance measure (the English Baccalaureate advocates subjects such as history or geography as compulsory to its attainment) (DfE, 2013). It is important to acknowledge that one of the schools involved in this research insisted that students study either history or geography as part of their Key Stage 4 pathway. It was explained that this requirement was a direct result of the English Baccalaureate performance measure. This disclosure then questions the extent to which students have a real choice in their educational pathway, restricting selection of certain subjects. Consequently, it may be inaccurate to expect that data related to the selection of either subject in this 
school sample is representative of real choice. It is not known whether the other two schools operate by the same principles, and what the potential implications of this might be. The results of this sample are in contrast to the findings of Adey and Bibbulph (2001), who propose that the studying of history and geography is in decline. Caution must be exercised when referring specifically to history and geography, as the current study classified such subjects into an overarching category (humanities), and hence it cannot directly confirm or disprove the impact of each subject specifically.

The results of the present study also demonstrate that males hold a higher academic self-perception than their female counterparts. Although this difference was small (Cohen, 1988), it illustrates that gender differences in perceived academic ability are apparent within the sample. These findings are consistent with other studies previously documenting males to generally rate themselves as more academically able than females (McCrone et al., 2005). Research by Moon et al. (2004) highlighted that males and females are often influenced in accordance with gender stereotypes; thus, when considering traditional patriarchal viewpoints (which advocate male superiority within society) it may be that this gender trend in academic self-perception is derived and maintained through the principles of socialisation and modelling (Bandura, 1977). This increased academic self-perception of males finds little support in current performance statistics, which recognise that females tend to out-perform males (McCrone et al., 2005).

In contrast, other research has suggested that perceived academic ability is often consistent with actual ability (Atkinson, 2006). Colley and Comber (2003) proposed that academic ability may be related to the selection of educational direction (in terms of entering an academic or vocational pathway). However, the categorisation of subjects within the current study did not discriminate between the two educational routes. For example, subjects such as 'health and beauty' (NVQ) were incorporated alongside other traditional subjects such as 'art' (GCSE); these were both included in the 'creative and performance' category. Researchers choosing to classify subjects in a different way may achieve contrasting results to those reported herein. It was further evidenced that perceived academic ability, as measured within this sample, did not predict the up-take of any of the optional subjects under investigation. Therefore, while the self-perception of academic capability differed between males and females, it was not shown to directly relate to a specific subject for either group in this sample.

It has been shown that males and females in this sample hold similar attitudes toward school. These results are in contrast to other research which has suggested that females generally have a greater overall positive attitude to education than males (Light- body, Siann, Stocks, \& Walsh, 1996). Francis (2002) also noted a difference suggesting that males are often more relaxed in their approach to education than females. Although a difference in attitude has been recognised herein, the research design did not allow for the specific identification of pertinent factors. It has previously been considered that parents (Moon et al., 2004), teachers (Ashworth \& Evans, 2001), pedagogies (Lord \& Harland, 2000), enjoyment (Adey \& Biddulph, 2001) and ability (Atkinson, 2006) can contribute to an individual's attitude toward school. Future exploration of potential influences is worthy of consideration in light of the unexpected trends demonstrated herein.

While the findings of the current study are supported by existing research (for example, McCrone et al., 2005; Colley \& Comber, 2003), there are several potential limitations which warrant consideration. Firstly, the data analysed herein pertain to three secondary schools within a localised area. Therefore, the results are potentially socially and/or culturally specific and may consequently not be generalisable to all students entering upper secondary education. Nonetheless, the sample size is sufficient to propose that the findings provide a moderate indication of the predictors relevant to subject selection in the student population.

The decisions relating to the classification of school subjects into specified categories for statistical analysis may also be considered a limitation of the study. It has been considered that allocating certain subjects to a group may have had some impact on the results. However, in order to promote discriminatory power, it was necessary to categorise individual subjects with others of a similar style. For example, psychology was subsumed within the 'humanities' category in line with critical psychological perspectives suggesting that this subject should be aligned with the humanities (Wetherell, 1996). Future research in this area may choose to classify psychology as 'science'. Such subtleties should be acknowledged for comparative purposes and accuracy of suggestions. The study has clearly outlined the format of this categorisation, being advantageous for other studies which may wish to replicate the current research design.

These limitations notwithstanding, the results of the study show a trend of subject choice being related to gender. The reliability of the current study findings are enhanced by the employment of validated measures (McCoach, 2002; Boldizar, 1991) and are consistent with other study findings. The documented findings provide evidence to support the previous research on gender differences and academic self-perception (Reiss, 2001), while challenging existing research on attitudes towards school (Francis, 2002). Gender was shown to be the strongest predictor of subject selection within this sample, and this 
related specifically to physical education/sport and business/ICT. This study has shown that girls are less likely than boys to opt for these subjects (in contrast to creative and performance subjects), with the findings offering little indication of why such gender differences exist. In light of the current results, it is therefore necessary that further research be conducted to monitor the outcomes of this study in relation to subject selection in preparation for Key Stage 4 .

In terms of practical implications, the recognition of a negative attitude of females towards the up-take of physical education and business studies requires intervention. It may therefore be necessary to conduct associated research to ascertain possible solutions to this gender divide. Females may be able to directly advise on the requirements for the neutralisation of such subjects. Future research needs to be refined in order to enhance specific knowledge pertinent to this area. Replicative studies would also be advantageous in promoting further validation of the current research findings which show that males and females hold similar attitudes toward school. This may contribute towards the recognition of a potential attitudinal shift. Furthermore, studies may consider exploring the extent to which academic perceptions relate to inherent or social factors and, more specifically, what these factors may be. It would also be beneficial to consider exploring the extent to which schools adopt 'gender sensitive' pedagogies (Sinnes, 2006). In acknowledging individual experiences and conceptions of academic subject areas, more consideration can be given to alternative teaching and assessment methods for the core subjects.

\section{RefERENCES}

Adey, K., \& Biddulph, M. (2001). The influence of pupil perceptions on subject choice at $14+$ in geography and history. Educational Studies, 27, 439-450.

Ashworth, J., \& Evans, J. L. (2001). Modelling student subject choice at secondary and tertiary level: a cross-section study. Economic Education, 32, 311-320.

Atkinson, C. (2006). Key Stage 3 pupils views about reading. Educational Psychology in Practice, 22, 321-336.

Bandura, A. (1977). Social Learning Theory ( $2^{\text {nd }}$ ed.). Engelwood Cliffs, NJ: Prentice-Hall.

Bem, S. L. (1974). The measurement of psychological androgyny. Consulting and Clinical Psychology, 45, 155-162.

Blickenstaff, J. C. (2005). Women and science careers: leaky pipeline or gender filter? Gender and Education, 17, 369-386.

Boldizar, J. P. (1991). Assessing sex typing and androgyny in children: the Children's Sex Role Inventory. Developmental Psychology, 27, 505-515.
Brown, C. A. (2010). Can legislation reduce gender differences in subject choice? A survey of GCSE and A level entries between 1970 and 1995. Educational Studies, 27, 173-186.

Cohen, J. (1988). Statistical Power Analysis for the Behavioural Sciences ( $2^{\text {nd }}$ ed.). Hillsdale, NJ: Erlbaum.

Colley, A., Comber, C., \& Hargreaves, D. J. (1994). Gender Effects in School Subject Preferences: a research note. Educational Studies, 20, 13-18.

Colley, A., \& Comber, C. (2003). School Subject Preferences: Age and gender differences revisited. $E d-$ ucational Studies, 29, 59-67.

Crombie, G., Sinclair, N., Silverthorn, N., Byrne, B. M., DuBois, D. L., \& Trinneer, A. (2005). Predictors of young adolescents' math grades and course enrollment intentions: Gender similarities and differences. Sex Roles, 52, 351-367.

Cronbach, L. J. (1951). Coefficient alpha and the internal structure of tests. Psychometrika, 22, 297-334.

Davies, P., Telhaj, S., Hutton, D., Adnett, N., \& Coe, R. (2008). Socioeconomic background, gender and subject choice in secondary schooling. Educational Psychology, 5, 235-248.

DfE. (2013). English Baccalaureate. Available at: http:// www.education.gov.uk [Accessed $20^{\text {th }}$ July 2013].

Festinger, L. (1954). A theory of social comparison processes. Human Relations, 7, 117-140.

Francis, B. (2000). Boys, girls and achievement. Addressing the classroom issues. London: RoutledgeFalmer.

Francis, B. (2002). Is the future really female? The impact and implications of gender for 14-16 year olds career choices. Education and Work, 15, 166-220.

Francis, J., Khurana, I., \& Pereira, R. (2003). The role of accounting and auditing in corporate governance and the development of financial markets around the world. Asia-Pacific Journal of Accounting and Economics, 10, 1-30.

Ireson, J., Hallam, S., \& Hurley, C. (2001). Ability grouping in the secondary school: Effects at Key Stage 4. Final Report to the Nutfield Foundation. London: University of London, Institution of Education.

Lightbody, P., Siann, G., Stocks, R., \& Walsh, D. (1996). Motivation and Attribution at Secondary School: the role of gender. Educational Studies, 22, 13-25.

Linnenbrink, E. A., \& Pintrich, P. (2003). The role of self-efficacy beliefs in student engagement and learning in the classroom. Reading and Writing Quarterly, 19, 119-137.

Lord, P., \& Harland, J. (2000). Pupils' Experiences and Perspectives of the National Curriculum: Research Review [online]. Available: http://www.qca.org. uk/254_1956.html [7 January, 2005].

McCoach, D. B. (2002). A validation study of the School Attitude Assessment Survey. Measurement 
and Evaluation in Counselling and Development, 35, 66-77.

McCrone, T., Morris, M., \& Walker, M. (2005). Pupil Choices at Key Stage 3 - Literature Review. London: DfES.

Moon, S., Lilley, R., Morgan, S., Gray, S., \& Krechowiecka, I. (2004). A systematic review of recent research into the impact of careers education and guidance on transitions from Key Stage 3 to Key Stage 4 (1988-2003). In: Research Evidence in Education Library. London: EPPI-Centre, Social Science Research Unit, Institute of Education, University of London.

Muzzatti, B., \& Agnoli, F. (2007). Gender and mathematics: Attitudes and stereotype threat susceptibility in Italian children. Developmental Psychology, 43, 747.

Reiss, M. J. (2001). How to ensure that pupil's don't lose interest in science. Education Today, 51, 34-40.

Rice, L., Barth, J. M., Guadagno, R. E., Smith, G. P. A., \& McCallum, D. M. (2013). The role of social support in students' perceived abilities and attitudes toward math and science. Youth and Adolescence, 42, 1028-1040.

Ryan, A. (2001). The peer group as a context for the development of young adolescent motivation and achievement. Child Development, 72, 1135-1150.

Sinnes, A. T. (2006). Approaches to gender equity in science education. Two initiatives in sub-Saharan African seen through a lens derived from feminist critique of science. Oslo: Unipub. http://www.ils. u10.no/forskninig/palidrgrad/doktorarhandlinger/ docs/AstridSinnes Avhandlingfeminist critque of science.oslo.

Skinner, B. F. (1974). About Behaviourism. New York: Alfred Knopf.

Thomas, W., \& Webber, D. J. (2009). Choice at 16: school, parental and peer group effects. Research in Post-Compulsory Education, 14, 119-141.

Wetherell, M. (1996). Defining social psychology. In: R. Sapsford (ed.), Issues for social psychology (pp. 5-18). London: Sage. 